\title{
Networking as Multi-Purposed Tool for Innovative Organizations in Rural Areas
}

\author{
Lívia Madureira $^{1, a}$, Teresa M. Gamito ${ }^{2, b}$ and Dora Ferreira ${ }^{3, c}$ \\ ${ }^{1}$ University of Trás-os-Montes e Alto Douro (UTAD), Department of Economics, Sociology and \\ Management (DESG). Centre for Transdisciplinary Development Studies (CETRAD). Quinta de \\ Prados, 5000-801, Vila Real, Portugal \\ ${ }^{2}$ University of Lisbon (UL), Instituto Superior de Agronomia (ISA), Tapada da Ajuda, 1349-017 \\ Lisboa, Portugal \\ ${ }^{3}$ Centre for Transdisciplinary Development Studies (CETRAD). Quinta de Prados, 5000-801, Vila \\ Real, Portugal \\ amadurei@utad.pt, 'btmgamito@mail.telepac.pt, ${ }^{\mathrm{c}}$ dorairferreira@gmail.com
}

Keywords: Innovation, Networking, Networking innovation, Hidden innovation, Rural areas.

\begin{abstract}
This paper builds on the findings of a survey to the innovative organizations located in Portuguese rural areas. This survey has been underlined and applied in the context of the project RUR@L INOV. The paper has two goals: to explore how networking is used by rural-based organizations and, second, to discuss how networking could be promoted by public policy to boost collaborative innovation. The evidence presented and discussed indicates that networking is used by rural-based innovators as a multipurposed tool including the establishment of networks to obtain scale/scope effects and/or access local, mostly intangible, resources of rural areas. However, conventional innovation networks, usually led by R\&D units or top-associations don't appear as a significant resource for most of the innovators. Probably, due to the organizations smallness, the high qualification of innovation leaders, together with their entrepreneurial attitude, these innovators search for knowledge and other resources by their own means and initiative. Nevertheless, this entrepreneurial attitude towards knowledge, information and skills demand could be shared by other, both existing organizations and new-entrants in the rural economies, through new networking models led by the innovators.
\end{abstract}

\section{Introduction}

Innovation has been placed at the heart of the Europe 2020 strategy for growth and jobs [1]. EC [1] highlights that Europe's future economic growth and jobs creation will increasingly have to come from innovation in products, services and business models. However, so far, the public support to innovation has been oriented towards technological product and process innovation. This is largely due to the major impact in growth of these types of innovation. The problem with this policy-bias (and, at large extent, research-bias too) towards technological innovation is the neglecting of non-technological innovation and small-scale innovations and innovators. The latter, namely the SME, are fundamental for jobs (creation and maintenance) at the EU level. Therefore, innovation research and policies need to focus on understanding, acknowledge and enhancing this low-profile innovation. This hidden innovation has in recent times started to be acknowledged and investigated by a growing number of researchers (e.g. [2], [3], [4], [5], [6], [7]). Hidden innovation includes non-technological innovations, such as marketing and organizational, product and process innovation not mainly based on R\&D inputs, and the non-technological innovation mingled in the technological innovation (e.g. [8], [9], [10]). In addition, as has been recently acknowledge by [11], most of the innovation is a result of processes where different types of innovation are mixed, such as combinations of product and marketing innovation, mixes of marketing and organizations together with product (and often process) innovation. OECD [11] acknowledges also an increasing role of the collaborative approaches in the innovation development and that this entails the participation of a diversity of players in innovation processes. 
Therefore, to obtain insightful knowledge on hidden innovation there is a need for broader concepts of innovation, inclusive units of analysis, and flexible tools for data collection. A framework built on these three pillars was developed by the project RUR@L INOV which aimed at identifying and describing the processes of innovation developed by the organizations (firms and others) operating in the Portuguese rural areas, as well as to develop a methodological framework to assess innovation accounting for processes and not limiting to the innovation inputs and outputs $[12,13,14]$. This later framework consisted on identifying and developing an indicators system able to identify, describe and rate critical dimensions of innovation at the organization level for the case of the organizations located in rural areas. The major novelty of this innovation assessment framework was the inclusion of relevant variables to weigh the innovation processes. These variables included the type of innovations and their mixes, the internationalization dynamics, the knowledge mobilization patterns, distinguishing different types of knowledge, namely local-based, the networking activities, the diversification strategies and the local-specific features. This framework was applied to the database generated by a survey that has been applied, during the period September 2012 to January 2013, to a sample of 120 organizations. The organizations were selected from a universe previously identified recurring to several information sources. The surveyed organizations were located across all Portuguese (Continental) rural territory (rural NUTS3 according to OECD classification). The survey was based on a broad concept of innovation, entailed the description of innovations processes instead of assuming pre-defined innovation categories and patterns, like the approach followed by the CIS (Community innovation survey), and was applied to diverse type of organizations, firms, non-profit and public organizations operating in different activity sectors and encompassing all organizations of all economic sizes, from individual business to large-companies.

The survey results highlighted the diversity of innovators. The surveyed innovative organizations show different organizational models, operate in different sectors, supply a multiplicity of different (and differentiated) products and services, alongside with the fact of presenting diverse innovation patterns. Nonetheless, they share a high qualification profile, both of the innovation leaders and the organization' human resources, in particular in the case of micro-size organizations, and also a continuous and cumulative innovations pattern. The entrepreneurial attitude is another common trait especially for the case of small and very small organizations. This attitude probably explains the fact that the innovators rely mostly on their internal knowledge and capabilities to innovate and that they demonstrate a noteworthy ability to mobilize latent resources in rural areas (e.g. local knowledge) to respond to latent demands of niches and special groups of consumers.

Formal collaborative arrangements for innovation development, for instances through the establishment of formal partnerships with R\&D units or the integration into innovation networks, are infrequent and in general adopted by innovation strategies of the large-companies. On the other hand, innovation networking namely addressing scale and /or scope economies or resources sharing are present but are still more a must than the rule. Given the importance assigned to networks and networking for rural development (e.g. [15], [16], [17], [18]) and the evidence obtained by the survey, that networking is a multi-purposed tool essential to most of the innovators, the goals of this paper is twofold. Firstly to explore how networking is used by the rural-based innovative organizations. Secondly to discuss how networking could be enhanced to boost the emergence of innovator-led networks able to inter-connect with other innovation players in order to enhance scale and scope economies, as well as to provide a learning tool to new-entrants. This dynamic of newentrants is, in the Portuguese case, one of the social responses to the economic crisis and unemployment, namely of young and qualified individuals. However, they need the support of a learning structure to be able to assess the feasibility of their ideas and to get knowledge from others experiences.

In the next section is presented empirical evidence collected in the survey that allows for some insights on the paper goal of learning how networking is used by the rural innovators. The third section of the paper discusses this evidence and how the knowledge acquired by this survey, and 
other forms of interaction of the research team with the rural-based innovators (e.g. focus groups and learning seminars), could be used to promote networks enhancing collaborative approach to innovation and collective learning. Finally, general conclusions are presented.

\section{Networking strategies and activities of rural-based innovators}

The evidence gathered by the survey to the innovative rural-based organizations in Portugal shows that there is an intense collaborative action between innovators and other players, namely their peers as well other actors, such as the R\&D units, local authorities and sectorial and territorial associations (see Fig. 1).

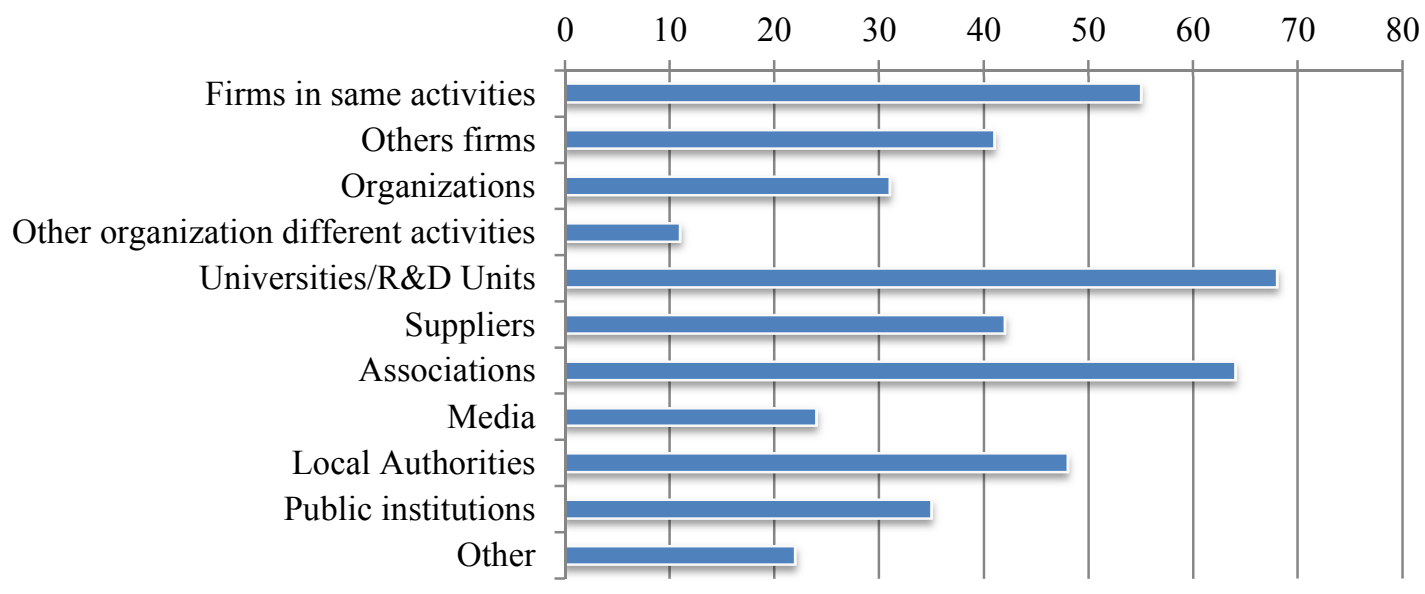

Fig. 1 -Number of organizations entailing collaborative action according type of partner

A total of 450 partnerships were reported by the 120 surveyed organizations. The more common partners are the peers' organizations, the R\&D units and sectorial and other associations. These partnerships are mostly informal and led by the innovative organizations according their needs and resources. Their main motivation is to gather resources such as funding and know-how when that is needed and/or the opportunity allow for it. That probably explains the little expression of organised networked collaborative action to innovation which entails stable and long run partnerships.

The analysis of innovation patterns shows that only a relatively small number of organizations (less than $20 \%$ of the total) developed networking innovation involving collaborative action with different partners, depending on the network motivation(s). Fig. 2 shows that innovative networking appears mostly connect with the organizations involvement with local community and with the aim of obtaining scale/scope economies at supply level.

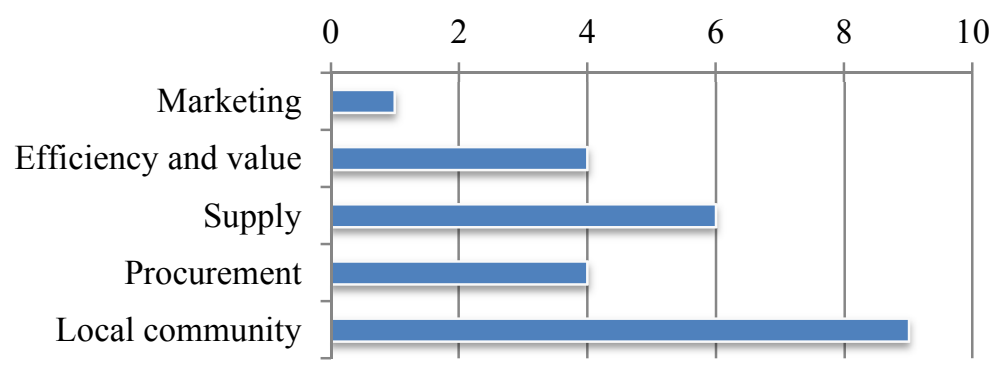

Fig. 2 - Number of organizations presenting network innovation

The only example of a network for marketing strategy is the case of a wholesale PGI fruit medium sized cooperative that developed, with a fruit producers association, a network of local sale points to sell PGI fruit directly to the consumers.

In what concerns the creation of networks to achieve efficiency and value gains we found four rather different organizations: a not for profit small organization that created a producers network to gain scale to discuss with the government the rules and laws that support the sector and also to 
make integrated marketing, both in Portugal and international markets; a nano (organization with less than 4 workers) private association that wholesales fruit productions that created an R\&D network, including universities, research laboratories, local partners and other firms to improve fruit varieties and create new by-products; and also related with the leverage of agro-forest resources, there are two not for profit services organizations that developed producers associations and partnerships with universities and laboratories to improve forestry products, in one case, and cereal varieties, on the other, and also to get and disseminate knowledge.

The organizations that created networks to obtain scale/scope economies at supply level include: three nano rural tourism firms, that created collaborative networks with other tourism firms and local institutions in order to offer a larger scope of touristic, recreational and even therapeutic activities and thus ensure a larger demand for their touristic accommodation and also to make integrated and international marketing; also in the tourism sector a nano not for profit organization that delivers touristic services that created a network to offer international marketing and sell different touristic products and packages; another not for profit large scale development organization, that created several producers networks in order to offer, directly to consumers, integrated packages of fruit and vegetables; a medium sized wine producers association that put in place a new organizational model, alternative to a cooperative, in order that the wine producers could share resources and skills but maintain self-trademarks.

As cases of the development of networks to get scale for procurement, we found: a micro gourmet chocolate industry that created a network with local cheese producers in order to produce different gourmet products; a private, micro rural tourism firm with diversified agro-industry activities that created also a collaborative network with other local firms (salt miners) to offer new gourmet products; a medium sized wine producer that formed with other firms a central purchasing organization to buy several materials for the wine industry (bottles, corks); and, finally a nano agriculture producer that formed a collaborative network with other producers for sharing transport and distribution costs.

Involved in the creation of networks with local communities we can find very different types of organizations, with also very different activities. In the tourism sector, a nano rural tourism firm promotes the involvement of the local population to integrate the tourists in the local traditional activities to ensure social sustainability and benefit from local knowledge. Two nano not for profit organizations, that provide touristic services, created collaborative networks with local people, one of them to develop rural activities for urban children and to reinforce intergenerational ties and the other to integrate local knowledge and local activities on the tourism packages. Another nano not for profit social organization developed a project that integrates local villages and communities in a network to provide environmental education and awareness and to involve older people in teaching children old traditions. Also on the social area, a large not for profit organization created a social integration network that allows users (mainly disabled people) to collaborate in the internal functioning of the organization. And a micro not for profit services organization that, through international partnerships, brings to Portugal volunteers to learn agro activities, has agreements with local people that produce and teach how to produce artisanal food products. On the public sector, a medium sized rural municipality created an innovation network to promote local and regional entrepreneurship and partnerships with universities and other organizations. And finally, on the private sector, a micro agroindustry is encouraging the local community to create donkeys in order to provide the raw material (donkey milk) for the industry and thus maintain a local species and contribute to the local development, while a medium sized farm (with diversified agro-forestindustry activities) involves the people from the nearby village on the farm safekeeping and as hunting guides benefiting from their local knowledge and as a way of good neighbourhood relationships. 


\section{Innovator-led networks as a tool to enhance collaborative action for innovation}

The examples presented of structured collaborative action show that the networks resulted, in general, from bottom-up initiatives led by the innovative organizations or resulted from situations where networking innovation has been used to created new organizational models able to cope with scale/scope supply problems.

In the majority of the cases, the networking initiative was led by the innovators that used networking as a resource to innovate, for instance to develop and/or differentiate products and services (e.g. tourism services and gourmet products) by involving the local community know-how and/or resorting to local suppliers of typical foodstuffs they use as ingredient to make their products different when addressing niche markets. These cases, whereas not yet generalised, evidence interesting collaborative innovation patterns involving local suppliers, local communities and their know-how, thus showing a high potential to enhance rural development. Therefore, innovation appears as an instrument to promote rural development at several dimensions. The availability of specific-location resources such as know-how, local and typical products, landscape, nature and cultural assets that allow for products and services differentiation makes these areas attractive to new business and new initiatives especially due to the availability of high-qualified human resources with an entrepreneurial attitude. Thus, there is an opportunity to enhance rural development through promoting innovation, namely to attract young and qualified people to depopulated and aged areas.

On the other hand, innovators show a strong ability to identify market opportunities and to gather knowledge and information using networking. Probably due to their high qualification and ability to intensively use ICT they use informal networking as a tool to obtain knowledge resources that they convert into skills and information to fulfil their product, process and organizational innovation needs. As a result of this process they are themselves important generators of knowledge, skills and experience. They are, but could be much more a resource for other potential innovators, both existing organizations and new-entrants in rural areas. How could public policies contribute to enhance this knowledge and skills transfer and exchange? They could do that by supporting innovator-led networks, designed according to innovators needs and availabilities and enabling to connect (virtually but also in presence) innovators among themselves and new-comers, as well as other innovation players.

\section{Conclusions}

A major conclusion from this paper focused on the networking strategies and activities of ruralbased innovative organization in Portugal is that networking is a multidimensional tool with a high potential to promote rural development trough innovation. To make that possible public policies, intended both to innovation and rural development, need to centre more on micro-level analysis not limiting to the regional level of innovation system. Actor-constructed innovation systems need to be acknowledged and promoted given they demonstrated a huge dynamic and resilience, namely in situation of economic crisis, and evidence a huge potential to constitute an innovation and rural development resource.

\section{References}

[1] Commission of the European Communities (CEC) (2013). State of the Innovation Union 2012 Accelerating change. Brussels: Commission of the European Communities, COM (2013), 149 final

[2] M. B.Jensen, B. Johnson, E. Lorenz and B. A.: LundvallForms of knowledge and modes of innovation. In: Research Policy, 36, (2007), pp. 680-693

[3] A. Arundel, C. Bordoy, M. Kanerva: Neglected innovators: how do innovative firms that do not perform R\&D innovate? Results of an analysis of the Innobarometer 2007 survey, $n^{\circ} 215$. INNO-Metrics Thematic Paper, European Commission, DG Enterprise, Brussels, 31 March (2008) 
[4] E. Kirner, S. Kinkel, A. Jaeger: Innovation paths and the innovation performance of lowtechnology-firms - an empirical analysis of German industry. In: Research Policy, 38, (2009), pp. 447-458

[5] J.L. Hervas-Oliver, J. Albors-Garrigos, J. J.: Baixauli Beyond R\&D activities: the determinants of firms' absorptive capacity explaining the access to scientific institutes in low medium-tech contexts. In: Economics of Innovation and New Technology, 21, (2011), pp. 1-27

[6] C. S. Pereira, F. C. Romero: Non-technological Innovation: Current Issues and Perspectives. In: Independent Journal of Management \& Production, 4, (2013), pp. 360-376

[7] A. Trigo: The nature of innovation in $R \& D$ - and Non-R\&D-intensive service firms: Evidence from firm-level latent class analysis. In: Industry and Innovation, 20, (2013), pp 48-68

[8] H. Boer, W.: During, Innovation, what Innovation? A Comparison between Product, Process and Organisational Innovation. In: International Journal of Technology Management, 22, (2001), pp. 83-109

[9] A. M. Baranano: The non-technological side of technological innovation: State-of-the-art and guidelines for further empirical research. In: International Journal of Entrepreneurship and Innovation Management, 3, (2003), pp. 107-125

[10] T. Schmidt, C.: Rammer, Non-technological and Technological Innovation: Strange Bedfellows?, ZEW Discussion Paper (2007)

[11] OECD (2010), The OECD Innovation Strategy: getting a head start on tomorrow. OECD, Paris

[12] L. Madureira, T. M. Gamito, D. Ferreira, J. Portela: Inovação em Portugal Rural. Detetar, Medir e Valorizar, Princípia, Lisboa (2013)

[13] L. Madureira, T. M. Gamito, D. Ferreira, I. Oliveira: Innovation inputs and processes: the reality out of the box in the Portuguese rural áreas. In: T. Noronha, J. Gomes (org.): Innovation for sustainability and networks, University of Algarve Book Series(2013).

[14] T. M. Gamito, L. Madureira, J. Portela, D.: Ferreira Measurement of good practices of innovation in rural areas. In: T. Noronha, J. Gomes (org.): Innovation for sustainability and networks, University of Algarve Book Series (2013)

[15] G. Brunori, A. Rossi: Synergy and Coherence through Collective Action: Some Insights from Wine Routs in Tuscany. In: Sociologia Ruralis, 40, (2000), pp. 409-423

[16] J. Murdoch: Networks a new paradigm of rural development? In: Journal of Rural Studies, 16, (2000), pp. 407-419

[17] A. Copus, D. Skuras: Business Networks and Innovation in Selected Lagging Areas of the European Union: A Spatial Perspective. In: European Planning Studies, 14, (2006), pp. 79-92

[18] G. Thiele, A. Devaux, I. Reimoso, H. Pico, F. Montesdeoca, M. Pumisacho, J. A. Piedra, C. Veloso, P. Flores, R. Esprella, A. Thomann, K. Manrique, D.: Horton Multi-stakeholder platforms for linking small farmers to value chains: evidence from the Andes. In: International Journal of Agricultural Sustainability, 9, (2011), pp. 423-433 